\title{
PRIMENA LAMBDA FAZI MERE I ŠEPLIJEVE VREDNOSTI NA PROCENE PERFORMANSI ROBE U SKLADIŠTIMA
}

\section{Endre Pap, Ana Blagojević*}

Univerzitet Singidunum, Beograd, Srbija

Odgovorno lice:

Ana Blagojević

e-pošta:

asimicevic@singidunum.ac.rs
Rezime:

Klasična teorija mere se bavi proučavanjem skupovnih funkcija koje praznom skupu dodeljuju nulu i imaju osobinu aditivnosti. Takve skupovne funkcije se nazivaju merama. Uprkos širokoj primeni u različitim oblastima kako matematike tako i u rešavanju praktičnih problema, njihova primena zbog same osobine adtitivnosti je ograničena. Stoga se razvila teorija fazi mere u kojoj se polazi od skupovne funkcije koja pored osobine da je na praznom skupu nula, ima osobinu monotonosti, dok u opštem slučaju ne mora da bude aditivna. Ovakve skupovne funkcije predstavljaju uopštenje mere i nazivaju se monotone skupovne funkcije ili fazi mere. Određivanje fazi mere je kompleksan proces zbog eksponencijalnog broja podskupova nad kojima se mera procenjuje. Da bi smanjili složenost izračunavanja koristi se specijalna vrsta fazi mere pod nazivom $\lambda$-fazi mera. $U$ ovom radu opisan je problem određivanja parametra $\lambda, \lambda$-fazi mere i Šeplijeve vrednosti pri proceni performansi robe u skladištima.

Ključne reči:

$\lambda$-fazi mera, višekriterijumsko odlučivanje, indeks važnosti, Šeplijeva vrednost.

\section{UVOD}

Višekriterijumsko odlučivanje (Multiple criteria decision making, MCDM) odnosi se na problem izbora alternativa vezanih za više kriterijuma, videti [1]. Od 50-tih godina prošlog veka pa do danas razvio se veliki broj MCDM metoda koje se međusobno razlikuju u pogledu zahtevanog kvaliteta i kvantiteteta informacija, korišćene metodologije i matematičkih osobina koje treba da potvrde. Vince je u [1] sažeto podelio MCDM u tri grupe: teorija korisnosti na bazi višestrukih atributa, metode rangiranja i interaktivne metode. Carlsson i Fuller navode da postoje različite vrste MCDM metoda, videti [2]:

1. Metode rangiranja

2. Metode bazirane na teoriji korisnosti i vrednosti

3. Programiranje sa višestrukim ciljevma

4. Metode bazirane na grupnom odlučivanju i pregovaranju 
Većina MCDM metoda bavi se diskretnim alternativama, koje su opisane nizom kriterijuma. Informacije mogu da budu precizno utvrđene ili fazi utvrđene, $u$ intervalima. Jedan od problema koji se javlja pri rešavanju MCDM-a, je izbor agregacione procedure za rešavanje problema odlučivanja. U kontekstu višekriterijumskog odlučivanja, odluke se često donose na bazi nepreciznih, nesigurnih, i nekompletnih informacija koje dolaze od nekoliko manje ili više pouzdanih izvora. Teorija verovatnoće je razvijena zbog neizvesnosti ili nedostatka znanja o mogućim stanjima alternativa. Evidenciona racionalna teorija, koja predstavlja nastavak teorije verovatnoće, je čuvena alatka za odlučivanje usled neizvesnosti, videti [3]. Međutim, neizvesnost je neprecizna i neizvesna u mnogim situacijama i ne može se modelirati verovatnoćom. Da bi se ova vrsta neizvesnosti prevazišla predložena je teorija fazi skupova. Akcije su jedan od najvećih problema maloprodajnih lanaca, jer direktno dovode do gubitka prodaje, smanjenja profita i potencijalnog gubitka kupaca. $U$ ovom radu korišćena je $\lambda$ -fazi mera i Šeplijeva vrednosti da bi se odredio odnos između različitih atributa jedinice za vođenje zaliha i performansi maloprodajnih zaliha.

\section{LAMBDA FAZI MERA I ŠEPLIJEVA VREDNOST}

Kao efikasna alatka za merenje interakcije između elemenata, fazi mera se definiše na sledeći način:

Definicija 1: Neka je $X=\left\{x_{1}, x_{2}, \ldots, x_{n}\right\}$ fiksni skup. $P(X)$ je skup svih podskupova skupa $\mathrm{X}$. Fazi mera na $\mathrm{X}$ je skupovna funkcija $\mu: P(X) \rightarrow[0,1]$, koja ispunjava sledeće uslove, videti [4],[5]:

1. $\mu(\varnothing)=0, \mu(X)=1$

2. Ako $A, B \in P(X)$ i $A \subseteq B$, tada važi $\mu(A)<\mu(B)$

Da bi utvrdili tavu fazi meru, mora se naći ukupno $2^{n}-2$ brojeva nad kojima se mera procenjuje, jer u skladu sa gore navedenom definicijom vrednosti $\mu(\varnothing)$ i $\mu(X)$, su uvek jednake nuli tj. jedinici. Očigledno je da je ovakav proces procenjivanja prilično složen. Da bi smanjili složenost izračunavanja, predložena je $\lambda$-fazi mera g koja se ponaša kao specijalna vrsta fazi mere, videti [6], [7], [8].

Definicija 2: Neka je $X=\left\{x_{1}, x_{2}, \ldots, x_{n}\right\}$ fiksni skup. Fazi mera g na $X$ naziva se $\lambda$-fazi fazi mera, ako zadovoljava sledeće uslove:
$g(A \cup B)=g(A)+g(B)+\lambda g(A) g(B)$

Gde je, $\lambda \in(-1, \infty)$ za svako $\forall A, B \in P(X)$ i $A \cap B=\varnothing$.

Teorema 1. Ako je X konačan skup $\bigcup^{n} x_{i}=X, \lambda$ -fazi mera g zadovoljava sledeću jednačinu:

$$
\begin{aligned}
& g\left(\bigcup_{i=1}^{n} x_{i}\right)= \\
& =\left\{\begin{array}{l}
\frac{1}{\lambda}\left(\prod_{i=1}^{n}\left[1+\lambda g\left(x_{i}\right)\right]-1\right), z a \_\lambda \neq 0 \\
\sum_{i=1}^{n} g\left(x_{i}\right), z a \_\lambda=0
\end{array}\right\}
\end{aligned}
$$

gde je $x_{i} \cap x_{j}=\varnothing$, za svako $i, j=1, \ldots, n$ i $i \neq j$.

$g\left(x_{i}\right)$ za podskup sa jednim elementom $x_{i}$ naziva se fazi gustina, označena kao $g_{i}=g\left(x_{i}\right)$, što predstavlja subjektivnu težinu kriterijuma $c_{i}$ u MCDM. Za interaktivan kriterijum generalno važi da je $\sum_{i=1}^{n} g\left(x_{i}\right) \neq 1$.

Specjalno za svaki podskup $A \in P(X)$ imamo da važi:

$$
g(A)=\left\{\begin{array}{l}
\frac{1}{\lambda}\left(\prod_{i \in A}[1+\lambda g(i)]-1\right), z a \_\lambda \neq 0 \\
\sum_{i \in A} g(i), z a \_\lambda=0
\end{array}\right\}
$$

Vrednost $\lambda$ može se jedinstveno utvrditi pomoću prethodne jednačine. Za $g(X)=1$ jednačina se svodi na:

$$
\lambda+1=\prod_{i=1}^{n}\left(1+\lambda g_{i}\right)
$$

\section{Teorema 2.}

1. $\lambda>0$ kada je $\sum_{i=1}^{n} g\left(\left\{x_{i}\right\}\right)<g(X)$

2. $\lambda=0$ kada je $\sum_{i=1}^{n} g\left(\left\{x_{i}\right\}\right)=g(X)$

3. $-\frac{1}{g(X)}<\lambda<0$ kada je $\sum_{i=1}^{n} g\left(\left\{x_{i}\right\}\right)>g(X)$ 
Bazirano na skupu aksioma, Šepli je predložio definiciju koeficijenta važnosti, koji se naziva Šeplijeva vrednost $\varphi_{i}(\mu, X)$ (kraće zapisano sa $\varphi_{i}(\mu)$ ), i definisao ga je na sledeći način, videti [9]:

$$
\begin{aligned}
& \varphi_{i}(\mu, X)= \\
& =\sum_{T \subseteq X \mid i} \frac{(n-t-1) ! t !}{n !}[\mu(T \cup i)-\mu(T)]
\end{aligned}
$$

gde $n, t$ označavaju kardinalnost skupova $X, T$ redom.

Na bazi prethodne jednačine mi znamo da je Šeplijeva vrednost očekivana vrednost ukupnog marginalnog doprinosa između elementa $i$ i bilo koje koalicije $T \subseteq X \mid i$. Na osnovu definicije fazi mere, lako je uvideti da za svako $i$, važi da je $\varphi_{i}(\mu) \geq 0$ i $\sum_{i=j}^{n} \varphi_{i}(\mu)=1$, što znači da je $\left\{\varphi_{i}(\mu)\right\}_{i \in X}$, težinski vektor, koji se naziva Šeplijev težinski vektor.

Kada je mera $\mu$ aditivna, imamo da je $\varphi_{i}(\mu)=\mu(i)$ , što pokazuje da nema interakcije između elementa $i$ i bilo koje koalicije $T \subseteq X \mid i$. U ovom slučaju Šeplijev težinski vektor se svodi na tradicionalan težinski vektor $\omega=\left(\omega_{1}, \omega_{2}, \ldots, \omega_{n}\right)^{T}$, gde je $\omega_{i}=\mu(i)$.

Kada $\mu$ nije aditivna, ako je $\varphi_{i}(\mu)>\mu(i)$, onda postoji komplementarna interakcija između elementa $i$ i bilo koje koalicije $T \subseteq X \mid i$. Ako je $\varphi_{i}(\mu)<\mu(i)$ , onda postoji redudantna interakcija između elementa $i$ i bilo koje koalicije $T \subseteq X \mid i$. Stoga, Šeplijeva težina ne samo da pruža meru važnosti kriterijuma, već takođe odražava njihove interaktivne karakteristike.

Kombinovanjem sa definicijom $\lambda$-fazi mere g i Šeplijeve vrednosti, lako je izračunati indeks važnosti $\varphi_{i}(g)$, za kriterium $i$ koji se izražava sledećom jednačinom:

$$
\begin{aligned}
& \varphi_{i}(g)= \\
& =\sum_{T \subseteq X \mid i} \frac{(n-t-1) ! t !}{n !} g(i) \prod_{j \in T}(1+\lambda g(j))
\end{aligned}
$$

Sledeći primer prikazuje određivanje parametra $\lambda \mathrm{i}$ fazi mere. Podaci su preuzeti iz Tabele 4 , videti [10], s tim što su vrednosti podeljene sa 2 . $U$ tabeli su prikazani sledeći podaci: prosečna prodaja, prosečna cena, nedostatak zaliha u centralnom magacinu, da li je proizvod na promociji ili ne, da li se automatski poručuje, kao i verovatnoća da proizvoda nema na stanju. Kako su prva dva podatka kontinualna, u ovom radu oni su upoređeni, tako što su izračunate Šeplijeve vrednosti za obe varijable.

\begin{tabular}{llllll}
$\begin{array}{l}\text { Table } 4 \\
\text { category }\end{array}$ & \multicolumn{4}{l}{ Descriptivestatisticsofthevariables forthemanufacturerrisk } \\
\hline Variable & Obs. & Mean & Std dev. & Min. & Max. \\
\hline avg_sales & 1563855 & 0.4971689 & 0.9021178 & 0 & 14.91257 \\
avg_price & 1563855 & 1.4928780 & 0.8573341 & 0.486092 & 3.970331 \\
st_out_dc & 1563855 & 0.1577934 & 0.3645473 & 0 & 1 \\
promotion & 1563855 & 0.1633783 & 0.3697106 & 0 & 1 \\
auto_ordr & 1563855 & 0.3574065 & 0.4792361 & 0 & 1 \\
stock_out & 1563855 & 0.0341950 & 0.1817298 & 0 & 1 \\
\hline
\end{tabular}

\section{PROCENA PERFORMANSI ROBE U SKLADIŠTIMA}

Radi lakšeg izračunavanja skup promenljivih iz tabele 4. označavamo sa X i savkoj promenljivoj dodeljujemo redom oznake a, b, c, d, e, f.

$$
\begin{aligned}
& X=\{a, b, c, d, e, f\}, \mu(X)=1, \\
& \mu(\{a\})=0.24859, \mu(\{b\})=0.74644, \\
& \mu(\{c\})=0.07889, \mu(\{d\})=0.08169, \\
& \mu(\{e\})=0.17870, \mu(\{f\})=0.01709 .
\end{aligned}
$$

Sada koristimo formulu (3) da izračunamo parame$\operatorname{tar} \lambda$. Kako je $\sum^{6} \mu\left(\left\{x_{i}\right\}\right)>\mu(X)$, očekujemo, na osnovu Teoreme 2 ., da važi $-1<\lambda<0$. Dobijamo sledeću jednačinu:

$(1+\lambda \cdot 0,24859) \cdot(1+\lambda \cdot 0,74644) \cdot(1+\lambda \cdot 0,07889) \cdot$

$\cdot(1+\lambda \cdot 0,08169) \cdot(1+\lambda \cdot 0,17870) \cdot(1+\lambda \cdot 0,01709)=\lambda+1$

Koja se nakon transformisanja svodi na jednačinu petog stepena:

$$
\begin{aligned}
& \lambda^{5} \cdot 0.000004+\lambda^{4} \cdot 0.00034+\lambda^{3} \cdot 0.00935+ \\
& +\lambda^{2} \cdot 0.10859+\lambda \cdot 0.58109+0.3514=0
\end{aligned}
$$

Metodom polovljenja nalazimo približno rešenje prethodne jednačine sa greškom koja je manja od $10^{-2}$. Broj koraka nalazimo iz uslova:

$$
\frac{b-a}{2^{n}} \leq 10^{-2} \Leftrightarrow n \geq 7
$$

Primenjujući metod polovljenja dobijamo niz aproksimacija tako što nalazimo sredinu intervala: 
$x_{1}=\frac{a+b}{2}=\frac{-1+0}{2}=-0.5$

a zatim, pomoću znaka funkcije $\left(f\left(x_{1}\right)>0\right)$ proveravamo u kojoj polovini intervala se nalazi koren jednačine. Isti metod se ponavlja na toj polovini intervala, sa novim a i b. Ponovo tražimo sredinu intervala i metod ponavljamo 7 puta. Sve vrednosti su date u tabeli:

Vrednost $\lambda=-0.6796875$ je traženo približno rešenje polazne jednačine.Sada na osnovu formule (1) izračunavamo preostale mere svih podskupova skupa X. Rezultati su prikazani u sledećoj tabeli:

$$
\begin{aligned}
& \mu\{a\}=0.24859 \\
& \mu\{a, b\}=0.868909 \\
& \mu\{a, b, c\}=0.901208 \\
& \mu\{a, b, c, d\}=0.932859 \\
& \mu\{a, b, c, d, e\}=0.998254 \\
& \mu\{a, b, c, d, e, f\}=1.00375 \\
& \mu\{a, b, c, d, f\}=0.939113 \\
& \mu\{a, b, c, e\}=0.970447 \\
& \mu\{a, b, c, e, f\}=0.976264 \\
& \mu\{a, b, c, f\}=0.907829 \\
& \mu\{a, b, d\}=0.902354 \\
& \mu\{a, b, d, e\}=0.971454 \\
& \mu\{a, b, d, e, f\}=0.97726 \\
& \mu\{a, b, d, f\}=0.908962 \\
& \mu\{a, b, e\}=0.942071 \\
& \mu\{a, b, e, f\}=0.948218 \\
& \mu\{a, b, f\}=0.875906 \\
& \mu\{a, c\}=0.31415 \\
& \mu\{a, c, d\}=0.378398 \\
& \mu\{a, c, d, e\}=0.511137 \\
& \mu\{a, c, d, e, f\}=0.52229 \\
& \mu\{a, c, d, f\}=0.391092 \\
& \mu\{a, c, e\}=0.454694 \\
& \mu\{a, c, e, f\}=0.466502 \\
& \mu\{a, c, f\}=0.327591 \\
& \mu\{a, d\}=0.316477 \\
& \mu\{a, d, e\}=0.456738 \\
& \mu\{a, d, e, f\}=0.468523 \\
& \mu\{a, d, f\}=0.329891 \\
& \mu\{a, e\}=0.397096 \\
& \mu\{a, e, f\}=0.409574 \\
& \mu\{a, f\}=0.262792
\end{aligned}
$$

\begin{tabular}{ccccc}
\hline $\mathrm{n}$ & $\mathrm{a}$ & $\mathrm{b}$ & $\mathrm{x}_{\mathrm{n}}$ & $\mathrm{f}\left(\mathrm{x}_{\mathrm{n}}\right)$ \\
\hline 1 & -1 & 0 & -0.5 & 0.086 \\
\hline 2 & -1 & -0.5 & -0.75 & -0.0271 \\
\hline 3 & -0.75 & -0.5 & -0.625 & 0.0284 \\
\hline 4 & -0.75 & -0.625 & -0.6875 & -0.0084 \\
\hline 5 & -0.6875 & -0.625 & -0.65625 & 0.0142 \\
\hline 6 & -0.6875 & -0.65625 & -0.671875 & 0.0076 \\
\hline 7 & -0.6875 & -0.671875 & $-\mathbf{0 . 6 7 9 6 8 7 5}$ & \\
\hline
\end{tabular}


$\mathrm{Na}$ osnovu formule (4) izračunavamo Šeplijevu vrednost $\varphi_{a}(\mu, X)=0.1244983$, koja predstavlja koeficijent važnosti varijable $a$, kao i Šeplijevu vrednost $\varphi_{b}(\mu, X)=0.4826678$ koja predstavlja koeficijent važnosti varijable $b$.

\section{ZAKLJUČAK}

U ovom radu opisan je problem određivanja parametra $\lambda, \lambda$-fazi mere, kao i Šeplijeve vrednosti, na primeru procene robe u skladištima. Zaključeno je da je Šeplijeva vrednost za prosečnu cene veća od Šeplijeve vrednosti za prosečnu prodaju. Na taj način Šeplijeva težina ne samo da pruža meru važnosti kriterijuma, već dolaze do izražaja interaktivne karakteristike datih kriterijuma.

\section{LITERATURA}

[1] J.P.Vincke, Ph Brans, A preference ranking organization method: The PROMETHEE method for MCDM, Management Science (1985), 641 -656.

[2] C. Carlsson and R. Fuller, Fuzzy multiple criteria decision making: Recent developments, Fuzzy sets and systems, 78(1996) 139-153.
[3] Shafer G.A., Mathematical Theory of Evidence, Princeton University Press, Princeton, 1976.

[4] D. Denneberg. Non-additive Measure and Integral. Kluwer Academic Publishers, Dordrecht, 1994.

[5] E. Pap. Null-Additive Set Functions. Kluwer Academic Publishers, Dordrecht, 1995.

[6] M. Sugeno: Theory of Fuzzy Integrals and its Applications, Ph.D. dissertation, Tokyo, Institute of Technology, 1974.

[7] U. Cherubini, Fuzzy measures and asset prices: accounting for information ambiguity, Appl. Math. Finance 4 (1997) 135-149.

[8] U. Cherubini, Fuzzy measures and asset prices: accounting for information ambiguity, Appl. Math. Finance 4 (1997) 135-149.

[9] Shapley L.S., A value for $\mathrm{n}$ person game, in: $\mathrm{H}$. Kuhn, A.Tucker, Contributios to the theory of games, Princeton University Press, Princeton 1953.

[10] G. Avlijaš, A. Simićević (sada Blagojević), R. Avlijaš, M. Prodanović, Measuring the impact of stock-keeping unit attributes on retail stock-out performance, OPERATIONS MANAGEMENT RESEARCH, 2015. 